\title{
DOSSIÊ
}

\section{O documentário Dzi Croquettes (2009) e a construção de uma memória marginal, do subterrâneo e do esquecimento sobre a contracultura na ditadura civil-militar no Brasil}

\author{
The documentary Dzi Croquettes (2009) and the construction of the \\ marginal memory, the underground and the oblivion about the \\ counterculture in the civil-military dictatorship in Brazil
}

\author{
Andrei Chirilã \\ Mestrando em História na UNIFESP - Guarulhos \\ orcid.org/0000-0003-0982-2740 \\ andreichirila1996@hotmail.com
}

\begin{abstract}
RESUMO: O presente artigo objetiva compreender a importância do documentário $D z i$ Croquettes (2009) como elemento de resgate de uma memória na historiografia da contracultura na década de 1970, buscando destacar não apenas o seu papel como elemento que retira o grupo teatral que dá nome ao filme do esquecimento, mas também como efetiva este processo de recuperação. De tal maneira, objetiva-se levar em conta não apenas como a memória e a dimensão pessoal se tornam pedras angulares na narrativa, mas como também a influenciam na forma como é transmitida ao público, destacando a posição do documentário entre uma posição de recuparação do passado e sua idealização e apreender como determinados aspectos são ignorados para se monumentalizar um passado para os espectadores.
\end{abstract}

PALAVRAS-CHAVE: Memória. Documentário. Cinema.

ABSTRACT: This paper aims to understand the importance of the documentary $D z i$ Croquettes (2009) as a tool to rescue a marginalized memory in the historiography about counterculture in the decade of 1970, focusing to highlight not only his role as a element that withdraw the theater group that names the film, but also how this recovery process takes form. Thus, aiming to take in account not only the memory and the personal dimension acts as cornerstones in the narrative, but also how they affect the way they are transmitted to the public, highlighting the documentary position between a position of recovery and idealization and apprehend how certain aspects are ignored to monumentalize the past focused on the viewers' perception.

KEYWORDS: Memory. Documentary. Cinema.

\section{Introdução}

Desde seu lançamento, o documentário Dzi Croquettes (2009), de Tatiana Issa e Raphael Alvarez impulsionou um interesse renovado pelo grupo, que atuou de 1972 a 
Revista do Corpo Discente do Programa de Pós-Graduação em História da UnB

EM TEMPO DE HISTóRIAS | Brasília-DF | n. 37 | p. 217-236 | jul./dez. 2020.

ISSN 2316-1191

1976 e representou uma novidade não apenas no campo teatral, como também trouxe ao público novas perspectivas sobre questões como gênero, identidade e sexualidade.

O ressurgimento do interesse pelo grupo que o filme trouxe, retirando-o de uma situação de apagamento na área acadêmica voltada tanto à análise sobre a contracultura quanto sobre o período da década de 1970, se expressou no âmbito acadêmico na produção de diversas teses, dissertações, artigos, etc., que partem da narrativa do filme como elemento fulcral de resgate de uma atuação que radicalizou e aprofundou os questionamentos trazidos por grupos pertencentes à contracultura, como a Tropicália (CASTELO BRANCO, 2006). Como exemplo destes trabalhos, podese citar a dissertação de mestrado de Adriano Barreiro Cysneiros, Da transgressão confinada às novas possibilidades de subjetivação: resgate e atualização do legado Dzi a partir do documentário Dzi Croquettes, de 2014 e o artigo de Djalma Thürler, Dzi Croquettes: Uma política queer de atravessamentos entre o real e o teatral, de 2011.

Produzido em 2009, o documentário se inicia com uma narração in off de Tatiana Issa falando de sua infância em meio ao grupo, seguindo-se à isto a cena de uma apresentação de Ciro Barcelos, ator, coreógrafo e ex-integrante do grupo. Após expor suas memórias, segue-se uma sequência onde datas de eventos importantes da Ditadura até 1968 são apresentadas, como o golpe, a promulgação do AI-5, o número de artistas exilados e peças, músicas e filmes censurados após o processo de endurecimento do Regime.

Esta sequência inicial, serve como uma introdução ao contexto histórico e político mais geral antes da apresentação da trajetória do grupo em si, como uma forma de fazer com que o espectador compreenda o contexto repressivo em que o grupo atuou. A exposição da conjuntura repressiva não tem apenas o intuito de ser uma breve mostra desconectada do resto do enredo, mas sim, de mostrar o quanto os Dzi Croquettes, com sua irreverência e uso de uma estética andrógina, representaram uma ruptura não apenas com as normas morais e sexuais do período, mas também serviram como um espaço de liberação da mentalidade repressiva.

Em seguida, seguem-se relatos que tomam como base as lembranças das apresentações do grupo e a descrição das trajetórias dos ex-integrantes falecidos, ${ }^{1}$ nas quais são expostas não apenas seus números nos espetáculos, mas seus aspectos pessoais, como forma de fornecer um retrato que os idealiza, mas também os humaniza. Isto se faz presente, por exemplo, ao descrever Lennie Dale, apontado como o responsável pela profissionalização do grupo. Ao mesmo tempo em que o mostra como alguém talentoso e carismático, a diretora inclui relatos de outros ex-integrantes

\footnotetext{
1 Dos treze integrantes originais, nove faleceram. Destes, quatro faleceram em decorrência da AIDS, como Lennie Dale (1936-1994), Cláudio Gaya (1946-1992), Eloy Simões (1951-1987) e Paulo César Bacellar (1952-1993). Três foram assassinados, alguns dos quais como Reginaldo de Poly (1949-1984), em circunstâncias até hoje não esclarecidas. Os outros dois, como Carlos Machado (1943-1987) e Wagner Ribeiro (1936-1994), faleceram após terem terem sido vítimas de latrocínio. Roberto de Rodrigues (19451989) faleceu em decorrência de um Acidente Vacular Cerebral. Rogério de Poly (1952-2014), faleceu em decorrência de um coma provocado pelo diabetes e pela Hepatite C. Este último não tem sua data de morte citada no documentário, pelo fato de ter falecido posteriormente à sua estréia.
} 
Revista do Corpo Discente do Programa de Pós-Graduação em História da UnB

Em TEMPO DE HISTóRIAS | Brasília-DF | n. 37 | p. 217-236 | jul./dez. 2020.

ISSN 2316-1191

que mostram os problemas que o mesmo teve com drogas e que afetavam sua convivência com o resto do grupo.

Mesmo que o enfoque do documentário não seja o de analisar as atrocidades cometidas pelo regime militar contra seus opositores ou de falar das campanhas persecutórias sobre a população homossexual durante o período, como o trabalho de Ocanha (2014), este ainda pode ser relacionado a outros filmes que têm como escopo compreender e refletir sobre o passado referente à Ditadura.

No contexto de inserção de novos sujeitos na historiografia sobre o período, devese destacar também a importância de novas fontes, como as audiovisuais, como elementos importantes para fornecer novas formas de percepção e tratamento do passado recente e seus impactos na atualidade.

Figura 1 - A sobreposição de imagens coloridas das apresentações e em preto-e-branco dos eventos ligados à Ditadura, tem como função mostrar a atuação do grupo como uma ruptura com o contexto opressivo dos Anos de Chumbo.

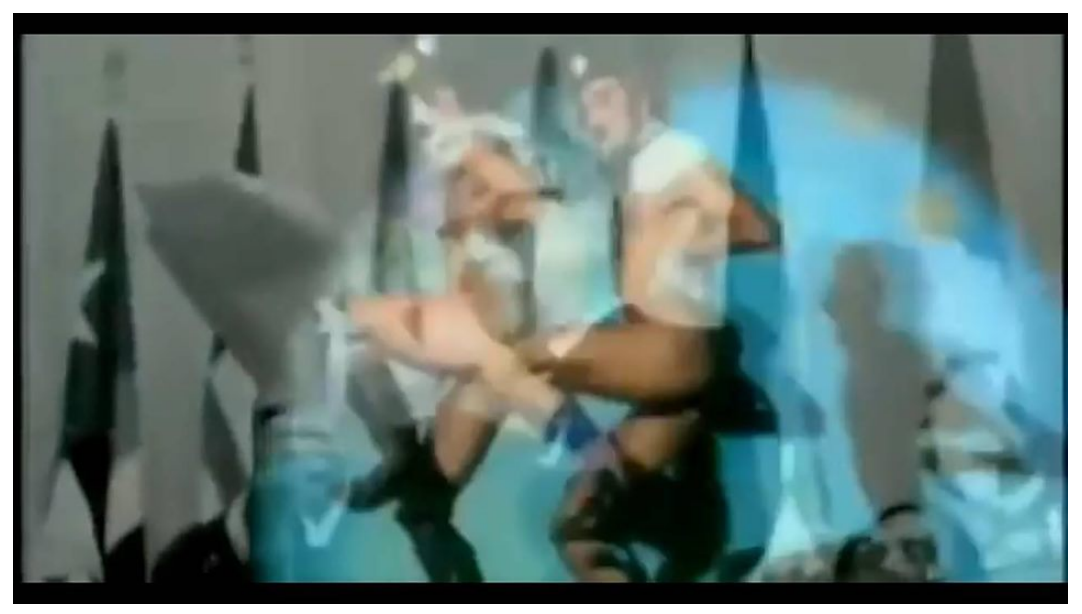

(DZI CROQUETTES, 2009, 00:02:58)

Portanto, como destaca Napolitano (2005), estando o historiador inserido em uma sociedade onde as imagens desempenham papel cada vez mais preponderante como elemento de comunicação, é necessário atentar-se às possibilidades que estas desempenham para se compreender novos enfoques em recortes espaço-temporais recentes, especialmente ao se referir a grupos marginalizados, quase sempre excluídos das fontes tradicionais.

O Cinema mostra-se um 'agente histórico' importante no sentido de que interfere direta ou indiretamente na História. Ou, mais propriamente, poderíamos acrescentar que o Cinema tem se mostrado um instrumento particularmente importante ou um veículo significativo para a ação dos vários agentes históricos, para a interferência destes agentes na própria História. [...] o Cinema também conservou obviamente a sua autonomia em relação aos poderes instituídos, e por isso ocorre que também tenha funcionado como Contrapoder. Neste sentido, se o Cinema com sua produção fílmica pode ser examinado como 'instrumento de dominação' e de imposição hegemônica, ele também pode ser examinado como meio de 'resistência'. Daí que as fontes associadas ao Cinema podem ser analisadas tanto como documentação 
Revista do Corpo Discente do Programa de Pós-Graduação em História da UnB

Em TEMPO dE HISTÓRIAS | Brasília-DF | n. 37 | p. 217-236 | jul./dez. 2020.

ISSN 2316-1191

\begin{abstract}
importante para compreensão dos mecanismos e processos de dominação, como também podem ser encaradas como documentação significativa que traz e revela dentro de si as múltiplas formas de resistências, as diversificadas vozes sociais (inclusive as que não encontram representação junto ao Poder Instituído), e de resto os variados padrões de representação associados a uma sociedade (BARROS, 2014, p.24).
\end{abstract}

Ao se falar da posição de marginalidade, é necessário destacar a questão de que o grupo não adotou por livre e espontânea vontade a posição de marginalidade, mas que este foi resultante de uma ação externa ao grupo, como destaca Pereira Júnior (2016). Primeiramente, pelo fato de ser um grupo teatral, não estava tão inserido na lógica da indústria cultural, ou seja, de produção, distribuição e consumo massificados como no caso do mercado fonográfico, por exemplo. Em segundo, há a questão da marginalidade enquanto experiência vivida, decorrente de sua posição enquanto grupo contracultural que se pautava em valores como a vivência coletiva (Pereira Junior, 2016, p.63-64).

Entretanto, é necessário destacar a posição de ambiguidade do documentário, que constantemente se desloca na dicotomia de hegemonia versus resistência. Embora se pretenda contra-hegemônico ao utilizar como protagonista de seu documentário um grupo de teatro tomado como símbolo de uma comunidade socialmente minoritária, ao mesmo tempo se insere nos meios hegemônicos enquanto parte da indústria cultural, voltado à ampla circulação e consumo. Desta forma, ao se inserir neste espaço hegemônico, sua posição enquanto parte da indústria cultural acaba influenciando a forma como constrói um discurso sobre o passado.

E visando o seu consumo e divulgação, há a utilização de uma narrativa ineditista, que visando atender às demandas do presente que se refletem mesmo nas produções culturais massificadas (Adorno; Horkheimer, 2009), como a representatividade da comunidade LGBTQIA+, constrói o documentário a partir de uma perspectiva idealizada que visa, como destaca Nichols (2010), atender as demandas de um público que anseia se fazer e se sentir representado. Isto se faz presente, por exemplo, no fato de a narrativa imprimir na marginalidade do grupo um posicionamento política e uma consciência de engajamento e defesa de pautas de um movimento posterior, que não estava presente no período em que o grupo atuou.

Ao trazer o debate sobre a contestação através da contracultura, é importante destacar no documentário o aspecto das ligações afetivas e pessoais com elementos que conduzem a narrativa a esta perspectiva idealizada. Como Issa destaca na sua entrevista ao portal Saraiva Conteúdo em 2010 e no filme, são as lembranças da convivência próxima com o grupo enquanto criança, visto que seu pai era cenografista da trupe, que servem de força motriz aos fatos apresentados no filme.

Desta forma, ao se utilizar das suas lembranças enquanto criança e dos depoimentos de ex-integrantes dos Dzi Croquettes para analisar a trajetória do referido conjunto, pode-se falar do documentário como parte de um conjunto maior de filmes brasileiros sobre o período dos Anos de Chumbo, como Batismo de Sangue (2007), de Helvécio Ratton; O que é isso companheiro (1997), de Bruno Barreto e Zuzu Angel (2006), de Sérgio Rezende. 
Embora compartilhe com estes o fato de tomar como ponto de partida o referido período, há um novo enfoque através da escolha de novos personagens para se abordar o período. Se os filmes citados tomam como eixo estruturante de suas narrativas a luta contra a Ditadura através do engajamento e da luta armada, o documentário Dzi Croquettes (2009) utiliza como enfoque de sua análise sobre o passado o papel do desbunde como um elemento de resistência através do uso da androginia e do humor. Desta forma, através de um novo enfoque, os diretores buscam destacar suas performances como elementos que impulsionaram uma mudança na mentalidade e nos comportamentos à época.

Entretanto, apreendeu-se através da análise fílmica, que por adotar uma narrativa muito mais focada em destacar o legado do grupo para a prosperidade do que sua atuação no período propriamente dito, os diretores não estabelecem uma relação aprofundada do surgimento do grupo com o contexto em que se inseriram, como a sua relação com outros grupos contraculturais que também atuaram à época da Ditadura. Ao contrário, o grupo é mostrado como um elemento inédito e improvável em um contexto de recrudescimento do regime, o que denota um tratamento ineditista.

De tal maneira, embora reconheça-se que seja importante reconhecer a importância do documentário como instrumento que traz novos olhares e possibilidades de discussão sobre o passado, vê-se como importante problematizar e analisar cirticamente a forma como o discurso fílmico busca recuperar um determinado passado e trazê-lo ao público, especialmente ao não se explorar de maneira mais profunda a atuação dos Dzi Croquettes com o contexto de mudanças comportamentais, sócioeconômicas e culturais que possibilitaram seu surgimento.

Pensa-se, portanto, a importância de estabelecer uma interlocução dos aspectos concretos como os contextos socioeconômicos, culturais e políticos, como trabalhados por Williams (2011), como fundamentais para que não apenas a atuação do grupo, mas também seu surgimento, sejam compreendidos de forma mais aprofundada e apurada para que se faça uma comparação crítica à forma como a memória deste é apresentada no filme.

No que tange a este aspecto, salienta-se que o filme, por mais que não tenha como seu cerne analisar os seus crimes, serve como um importante instrumento para demonstrar como o fechamento político após o Ato Institucional Nº 5 (AI-5) em 1968 teve impactos para muito além do âmbito político, tendo sufocado a vida cultural em prol da manutenção da ordem, como destacado pelos relatos de artistas como Ney Matogrosso, Elke Maravilha, Nelson Motta, entre outros, no trecho entre os instantes 00:03:08 e 00:06:24 e a inserção de uma imagem mostrando a quantidade de peças e obras censuradas após 1968, entre os instantes 00:01:43 e 00:01:49.

Em tal processo, o uso dos relatos se configura, tanto a nível cinematográfico quanto histórico, como importante instrumento de veiculação de lembranças sobre o período, não apenas como forma de historicizar a atuação do grupo, mas também como forma de mostrar ao público o contexto de recrudescimento da repressão e seus impactos na cena artística. 
Revista do Corpo Discente do Programa de Pós-Graduação em História da UnB

Em TEMPO DE HISTÓRIAS | Brasília-DF | n. 37 | p. 217-236 | jul./dez. 2020.

ISSN 2316-1191

Desta forma, os relatos adquirem uma função não apenas de sensibilizar o espectador sobre os impactos da Ditadura, mas também uma ferramenta que traz uma memória até então subterrânea (POLLAK, 1989) para a discussão pública. É fundamental destacar também o quanto a sua posição como meio de comunicação em massa possibilita amplificar as discussões sobre o passado que entremeiam o roteiro do filme. Entretanto, é fundamental destacar que, se documentário se posiciona como instrumento de recuperação destas mesmas memórias subterrâneas, por outro lado não há o questionamento das razões ligadas a este esquecimento.

Os próprios diretores, na entrevista ao portal eletrônico Saraiva Conteúdo, ressaltam que o grupo passou por este processo, mesmo tendo deixado para o teatro, artes e música um importante legado. Issa argumenta que a Ditadura censurou imagens referentes ao grupo, como gravações televisivas, embora também no documentário, não se explore se tal censura foi o único fator ou foi o mais preponderante para seu posterior esquecimento dentro da cena artística brasileira.

O enfoque muito mais centrado nestes aspectos do que a análise das razões que levaram o grupo a este esquecimento decorre da intenção e do formato da fonte. Se sua intenção é a de recuperar uma memória sobre o passado, como consequência, opta-se em utilizar a narrativa e os procedimentos cinematográficos com o intuito de mostrar o quanto o grupo é um elemento que legou contribuições à música e ao teatro e foi catalisador de mudanças comportamentais. Se os diretores partem do princípio de que o grupo já foi esquecido e o intuito do documentário é o de retirá-los desta posição, como consequência, sua abordagem será a de adotar um olhar que busca mostrar o quanto os Dzi Croquettes contribuíram para trasnformar a cultura e a mentalidade de um período específico, com reverberações ainda na atualidade.

Desta forma, através da comparação com os eventos históricos do período em que atuaram, busca-se sensibilizar o espectador a respeito de como o grupo representou uma ruptura radical com o fazer artístico e com as concepções de sexualidade durante a Ditadura. E, levando em conta o papel do documentário como instrumento de representação da realidade, como destaca Nichols (2010), a inserção de eventos históricos não tem uma função meramente decorativa na narrativa, mas sim a de tentar reconstruir eventos do passado e afirmar o protagonismo do grupo.

\begin{abstract}
A lógica que organiza um documentário sustenta um argumento, uma afirmação ou uma alegação fundamental sobre o mundo histórico, o que dá ao gênero sua particularidade. [...] A montagem no documentário com frequência procura demonstrar essas ligações. A demonstração pode ser convincente ou implausível, precisa ou distorcida, mas ocorre em relação a situações e acontecimentos com os quais estamos familiarizados, ou para os quais podemos encontrar outras fontes de informação. Portanto, o documentário apoia-se muito menos na continuidade para dar credibilidade ao mundo a que se refere do que o filme de ficção (NICHOLS, 2010, p.55-56).
\end{abstract}

Há também que se destacar ainda no que tange à inclusão dos eventos históricos, a forma como o documentário se apropria destes para confirmar um caráter de vanguarda de atuação do referido grupo. Portanto, deve-se levar em conta a forma como a narrativa media (Guilhermetti; Knuppel, 2011; Thompson, 1998) perante o público uma determinada visão sobre o passado através do uso de eventos históricos, 
Revista do Corpo Discente do Programa de Pós-Graduação em História da UnB

Em TEMPO dE HIStóRIAS | Brasília-DF | n. 37 | p. 217-236 | jul./dez. 2020.

ISSN 2316-1191

que são utilizados como ferramentas para confirmar as percepções dos diretores do grupo como elemento à frente de seu tempo.

Porém, mesmo não trabalhando as motivações para o esquecimento do grupo, levando em conta a importância que o documentário lhe confere no processo de recuperar sua trajetória, é necessário destacar o papel que este desempenha em gerar um interesse renovado sobre a atuação contracultural que se efetivou no período a partir da década de 1970 no Brasil, como mostrar as influências que este legou posteriormente. Entretanto, ao mesmo tempo busca-se destacar as problemáticas relativas à forma como o discurso fílmico constrói este passado e o traz a público de forma idealizada, conferindo-lhe um tratamento idealista que reflete muito mais um enfoque em responder questões do presente através do passado e compreender o legado do grupo na posteridade, do que analisar a sua atuação no período propriamente dito.

\section{(Re) Construindo uma memória marginalizada - O papel do documentário como elemento de recuperação}

Para se pensar o papel do documentário como instrumento que objetiva recuperar uma parte da memória relativa à contracultura e à homossexualidade, como já anteriormente expresso, é necessário destacar o contexto mais amplo em que o mesmo se insere. Este é marcado no âmbito historiográfico e cinematográfico pela preocupação em destacar como presente nos processos históricos, políticos, culturais e socioeconômicos o elemento marginalizado, compreendido aqui na concepção gramsciana, como elemento de destaque nas narrativas sobre o período da Ditadura Militar (1964-1985).

Portanto, há que se destacar o posicionamento do documentário como elemento que visa fornecer uma voz que, segundo os diretores na anteriormente citada entrevista ao portal Saraiva Conteúdo, havia sido renegada. Porém, se o próprio documentário destaca que a atuação do grupo foi esquecida na memória coletiva, não se discute o porquê desse esquecimento. Ou seja, não é expresso através da narrativa documental se tal apagamento é fruto da censura, indústria cultural ou pela homofobia.

Embora o que é narrada no documentário possa ser compreendio como uma narrativa sobre um grupo subalterno, no sentido de estarem marginalizados pela questão da homossexualidade dentro de uma sociedade heteronormativa conservadora, quanto por não se inserirem na indústria cultural do período e como elemento situado à margem de uma historiografia tradicionalmente focada nos eventos políticos a partir da perspectiva dos agentes estatais, é necessário compreender como o seu conteúdo é direcionado por questionamentos que partem do contexto presente.

Tal questão é perceptível, por exemplo, na intenção de mostrar o referido grupo como ponto de origem de um futuro movimento homossexual brasileiro. A ênfase constante a este aspecto, pode ser compreendida pelo fato do documentário ser elaborado, segundo Nichols (2010), levando em conta as questões trazidas pelo público, como por exemplo o LGBTQIA+. Desta forma, levando em conta a ampliação da visbilidade desta população e o papel do documentário enquanto elemento formador de 


\section{Historias}

Revista do Corpo Discente do Programa de Pós-Graduação em História da UnB

Em TEMPO dE HISTÓRIAS | Brasília-DF | n. 37 | p. 217-236 | jul./dez. 2020.

ISSN 2316-1191

opinião, segundo Isidio (2007), deve-se destacar o uso de uma narrativa idealizada com o intuito de conquistar um público através da afirmação de seu papel como vanguarda nas transformações culturais, políticas e sociais posteriores.

Figuras 2 a 5 - Como forma de confirmar o papel do grupo como algo influente para trasnformações culturais e comportamentais no período, há o uso recorrente da sobreposição de imagens de apresentações do grupo com relatos de artistas de destaque, que apresentam os Dzi Croquettes como símbolos de uma época ou como representantes de um nova possibilidades de vivência das identidades.

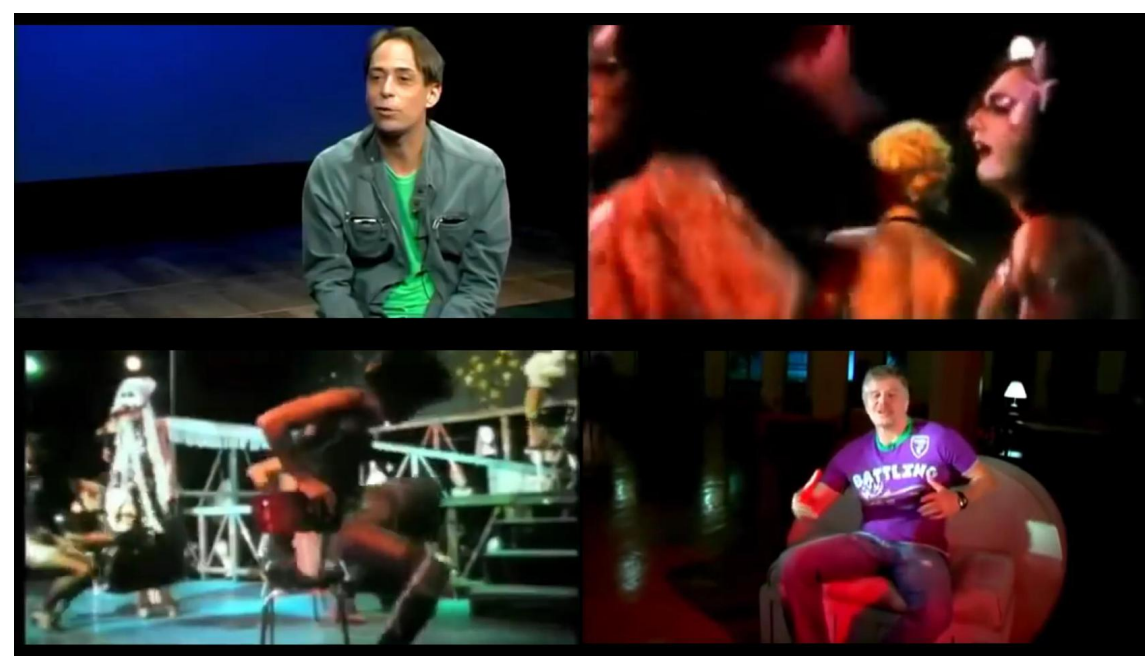

(DZI CROQUETTES, 2009, 00:11:05-00:11:40)

De tal forma, o documentário não deve ser analisado como algo deslocado do contexto cultural, político e social mais amplo em que se insere, relacionado unicamente com o desejo por parte da diretora, filha do cenógrafo da trupe, de recuperar memórias ligadas ao seu passado. Produzido em um contexto marcado pela conquista de visibilidade LGBTQIA+, o documentário, enquanto parte da indústria cultural, busca incorporar em sua narrativa a demanda social de representatividade destes setores. Isto é sensível ao mostrar sua atuação como elemento importante para mudanças no período da Ditadura. Este aspecto demonstra duplamente um anseio de conquistar um determinado tipo de público, como destaca Nichols (2010) através da inserção de seu desejo de se fazer representado no processo histórico, como também o fator de que a indústria cultural também é influenciada pelo contexto social à sua volta, segundo Adorno e Horkheimer (2009).

Em suma, há explícito no documentário um elemento importante de buscar inserir através de sua narrativa as vozes de setores antes marginalizados, como a população homossexual, nas narrativas sobre o passado, ainda que o filme trate a atuação do grupo de uma forma que a idealiza em decorrência da carga emocional das memórias e lembranças da diretora, dos ex-integrantes e de pessoas que conviveram com o grupo.

Embora haja uma novidade em incluir como protagonistas desta narrativa sobre a Ditadura a comunidade homossexual representada através do grupo, há em comum com filmes que já vinham sendo produzidos desde a década de 1960, por cineastas como Glauber Rocha, e posteriormente por outros, como Lúcia Murat na década de 1980 um aspecto comum em tentar compreender este período a partir do presente e 
Revista do Corpo Discente do Programa de Pós-Graduação em História da UnB

Em TEMPO dE HISTÓRIAS | Brasília-DF | n. 37 | p. 217-236 | jul./dez. 2020.

ISSN 2316-1191

dos seus questionamentos. Tais questionamentos, mesmo com enfoques e personagens diferentes e situando-se em conjunturas políticas, econômicas, sociais e culturais distintas, possuem em comum o fato de serem os elementos que organizam e estruturam o que é narrado perante e para o espectador.

Mesmo com o aspecto de adotar uma abordagem idealizada, é importante destacar como tanto o documentário dialoga com pesquisas historiográficas que vêm sendo desenvolvidas a respeito da homossexualidade na Ditadura e como ampliam as narrativas sobre o período, ao demonstrar os setores marginalizados como elementos também atuantes, tal como Ginzburg (2006) destaca ao falar na história vista a partir do ponto de vista daqueles que foram tradicionalmente excluídos de serem considerados como importantes de serem incluídos no processo histórico. No entanto, em decorrência da forma como essa recuperação se efetiva, não apenas através da narrativa em si, mas também por meio dos próprios procedimentos cinematográficos, é necessário problematizar como esta memória é trabalhada e ressignificada a partir do documentário.

Desta forma, ao destacar o citado grupo como elemento que rompeu com paradigmas de gênero e sexualidade no seu período, é importante ressaltar como este processo se efetiva através dos relatos de pessoas que assistiram aos espetáculos e do uso de filmagens do espetáculo, como forma de confirmar o papel do grupo neste processo. Tal aspecto é evidente no trecho entre os instantes 00:07:02 e 00:07:32 do filme, onde mostra-se um Lennie Dale, junto a dois outros atores, apresentando o espetáculo como sendo feito por atores que não são nem homens ou mulheres, mas simplesmente humanos. E também através do uso de relatos, entrecortados com cenas das apresentações, busca-se destacar também como o respectivo conjunto teve importante impacto na dança, música e teatro, como ao falar do grupo musical $A s$ Frenéticas como um produto da atuação dos Dzi Croquettes. Apontadas por Marília Pêra como "um resultado dos Dzi Croquettes" (DZI CROQUETTES, 2009, 01:01:1001:01:13). Da convivência com estes, traziam uma bagagem do humor e sensualidade como expresso por Regina Chaves, que assim como Lidoka e Leiloca, havia sido uma das tietes do grupo, além de Edyr de Castro, que embora não tivesse feito parte da versão feminina do grupo, era irmã de Carlos Machado, a Lotinha.

Ao sublinhar a importância dos Dzi Croquettes como representantes de uma alternativa frente aos modelos de masculinidades e feminilidades pautados em uma heteronormatividade rígida presente tanto na direita quanto na esquerda (Green, 2018) e como elemento que legou impactos à cultura brasileira posteriormente, apreende-se um olhar do presente em direção ao passado que possui como enfoque pensar sua herança na atualidade a partir da memória tanto da diretora, quanto dos ex-integrantes e de outros artistas que viveram no período. Isto se faz evidente no constante recurso à montagem paralela que, como destacado por Martin (2003), tem o objetivo de sugerir um significado a partir do seu confronto de acontecimentos distantes entre si no tempo com o intuito de comprovar perante o público, elemento consumidor do filme, os argumentos apresentados pelos diretores.

Um exemplo deste fator pode ser percebido entre 00:02:34 e 00:03:06, onde há uma sobreposição rápida de sequências em preto-e-branco dos eventos políticos às 
Revista do Corpo Discente do Programa de Pós-Graduação em História da UnB

EM TEMPO DE HISTóRIAS | Brasília-DF | n. 37 | p. 217-236 | jul./dez. 2020.

ISSN 2316-1191

sequências fartamente coloridas das performances dos Dzi Croquettes, com o intuito de mostrar as apresentações do conjunto teatral como um espaço de liberdade em meio ao controle cada vez mais intenso que o governo militar exercia sobre a sociedade.

Desta maneira, ao tentar recuperar a memória de e sobre um grupo até então marginalizado na historiografia sobre a contracultura ou sobre a Ditadura, o estilo narrativo adotado por Issa se relaciona a um aspecto fundamental do cinema periférico contemporâneo ao se voltar

\begin{abstract}
para a documentação do pequeno, do marginal, do periférico, mesmo que para isso se utilize de técnicas e formas de expressão (às vezes até equipe de produção) de origem central, metropolitana, hegemônica, marcando assim uma distância enorme da tradição cinematográfica terceiro-mundista dos anos sessenta. Ou seja, a diferença, a história e a identidade periféricas tal como representadas pelo cinema contemporâneo [...]. (PRYSTHON, 2010, p. 87 apud BRAGA, 2015, p.47).
\end{abstract}

O documentário, enquanto fonte, deve ser analisado de forma crítica em relação à forma como apresenta a atuação do grupo, idealizando-a e atribuindo-lhe características anacrônicas, como o epíteto de "revolucionário", que demonstra não um anacronismo, ignorando que à época, os grupos desbundados ou engajados eram encarados pelos seus integrantes como espaços completamente alheios um ao outro (Hollanda, 1981). Isto demonstra também o aspecto de elasticidade da memória, como argumenta Nora (1993), onde os limites entre passado e presente se sobrepõem.

E esta sobreposição entre temporalidades distintas, onde a partir do presente buscam-se referências para caracterizar o passado, como o já supracitado aspecto do citado grupo ser apresentado como precursor do movimento LGBTQIA+ brasileiro pode ser compreendida também como decorrente do próprio propósito do filme de afirmar o legado dos Dzi Croquettes na atualidade. Consequentemente, visando recuperar tal legado para o público contemporânea, busca conferir-lhes um prestígio através da afirmação de uma ligação do grupo com um movimento posterior ao seu surgimento, ignorando o fato de que este somente se consolidou a partir do final da década de setenta (Facchini, 2018).

Porém, levando em conta o fato da posição de marginalidade do grupo se fazer presente na escassez de registros de sua atuação na mídia e de suas memórias estarem fragmentadas, deve-se salientar a narrativa documental como espaço aglutinador destas através deste recurso, organizando-as de forma parcialmente linear. Simultaneamente, deve-se destacar o posicionamento das narrativas e lembranças de ex-integrantes e pessoas que conviveram com o grupo, assim como o uso de fotos e gravações pessoais dos bastidores como instrumento para preencher as lacunas resultantes da quase inexistência de registros na mídia tradicional, como a televisão².

\footnotetext{
2 Além do extra do DVD, composto pela gravação de uma apresentação realizada na televisão alemã, que Issa argumenta ser o único registro televisivo completo encontrado, durante o filme, há apenas dois um trechos de apresentações televisionada. Uma aparece brevemente entre 01:06:02 e 01:06:07, realizado no programa Fantástico, no ano de 1974. Outra, realizada no mesmo programa, mas no ano de 1988, mostra cenas de bastidores, entrevistas com os integrantes e as apresentações em si. Esta gravação aparece fragmentada entre diversos depoimentos, entre 01:28:56 e 01:29:06; 01:33:05 e
} 
Revista do Corpo Discente do Programa de Pós-Graduação em História da UnB

EM TEMPO DE HISTóRIAS | Brasília-DF | n. 37 | p. 217-236 | jul./dez. 2020.

ISSN 2316-1191

Neste aspecto, ao destacar seu protagonismo como grupo inovador em relação ao período em que atuou, há, como destaca Seixas (2008), a problemática de pensar a cultura como elemento autônomo e independente da atuação dos sujeitos, ignorando que estes em sua contemporaneidade, não são conscientes das mudanças estruturais que ocorrem.

Embora a importância do grupo na conjuntura em que atuou não possa ser ignorada, ao mesmo tempo deve-se levar em conta que

[...] o cinema mostra a realidade sem nunca se constituir em uma duplicata, na
medida em que o filme seleciona apenas alguns fragmentos, carregandoos de
sentido, tornando-os funcionais de maneira a compor uma história. Para
Sorlin, o problema não se restringe em saber se o filme se inspira ou não em
fatos verdadeiros, mas de que forma o filme é elaborado como narrativa que
sustenta uma visão sensível da história. A ficção é criada, partindo da idéia de
falso ou verdadeiro, assumindo-se como tal, e é através de sua difusão que ela
encontra uma conexão com o real. Dessa maneira, o filme transcreveria o real
através de instrumentos que lhe são próprios (SORLIN, 1977 apud
GUTFREIND, 2005, p.49).

Desta forma, o cinema não deve ser analisado como um retrato fiel da realidade, mas como elemento onde, através dos procedimentos fílmicos, quer sejam imagéticos, sonoros ou narrativos, reconstroem a realidade e a condensam para se encaixarem na estrutura do roteiro, que por sua vez seleciona aquilo que é considerado como mais importante de ser mostrado, como destaca Napolitano (2005).

Concomitantemente, deve-se destacar ainda dentro deste âmbito que, o tratamento da atuação do grupo por uma ótica ineditista, que como forma de representá-lo como elemento sui generis, acaba não levando em conta dois aspectos importantes. Estes são o desenvolvimento da contracultura brasileira e, como sublinha Diniz (2016) a conjuntura de surgimento de uma cultura homossexual nas grandes áreas urbanas, como o Rio de Janeiro, onde o grupo surge, em decorrência de maior exposição a novos hábitos motivados pela modernização e formação de uma cultura de consumo em decorrência do crescimento econômico. Ao não considerar alguns destes aspectos referentes ao contexto social, histórico, econômico, cultural e político, a narrativa acaba incorrendo em anacronismos que denotam uma preocupação em monumentalizar o passado e afirmar através dos relatos o caráter de originialidade do grupo, e que acaba não explorando o contexto circundante referente à contracultura e à homossexualidade.

Desta forma, ao atribuir-lhe características como "precursor do movimento LGBT brasileiro" como expresso na fala de Gilberto Gil em entrevista a Tatiana Issa no documentário, nota-se a presença de uma uma transferência aos seus membros de um protagonismo que denota um olhar idealizado do presente em direção ao passado. E a atribuição deste caráter visionário ao grupo se efetiva não apenas do uso de discursos que o idealizam, mas também por meio do uso de procedimentos próprios à linguagem cinematográfica, como a inserção de imagens das apresentações e 
Revista do Corpo Discente do Programa de Pós-Graduação em História da UnB

Em TEMPO DE HISTóRIAS | Brasília-DF | n. 37 | p. 217-236 | jul./dez. 2020.

ISSN 2316-1191

fotografias dos integrantes caracterizados, com o foco de convencer o espectador dos argumentos apresentados.

\begin{abstract}
A "verdade" das imagens não está baseada nas características minuciosas com que reproduz objetos ou pessoas, nos detalhes que contempla ou nos defeitos que dissimula. Sua capacidade de iludir, de apresentar uma coisa pela outra, pois é disso que se trata, deve ser procurada em outro lugar. [...] surge, assim, sempre como a re-presentificação de coisas e, principalmente, de pessoas. Ela nos coloca de novo em presença de. $\mathrm{E}$, não podemos esquecer que esta possibilidade só existe justamente pelo fato de que aquilo que lá está retratado, enquanto imagem, tem que estar obrigatoriamente distante ou no espaço, ou no tempo (MENEZES, 1996, p.84).
\end{abstract}

Tal procedimento é aqui compreendido como resultante de um enquadramento que está presente desde os momentos iniciais do filme quando Issa revisita suas memórias de infância ${ }^{3}$ e lhe atribui a conotação de um "grupo que iria revolucionar o Brasil” (DZI CROQUETTES, 00:02:33 - 00:02:34, 2009).

Porém, é interessante destacar como este aspecto atribuído se contradiz com a percepção dos próprios ex-integrantes sobre sua atuação no período. Tal aspecto se faz sensível na fala de Reginaldo de Poly, a "Pata", como era conhecido dentro do grupo, ao destacar que não estavam preocupados em pensar o que eram, apenas eram, como expresso no trecho entre os instantes 01:40:22 e 01:40:29 do documentário. Desta forma, percebe-se que este epíteto de precursor de um movimento que sequer havia sido formado é fruto muito mais de um olhar do presente de pessoas que conviveram com o grupo do que do grupo em si.

Como forma de destacar a importância das performances dos Dzi Croquettes em um contexto marcado pelo acirramento da repressão, censura e terrorismo de Estado, como destaca Cordeiro (2009), é importante sublinhar que os diretores se apoiam em um estilo narrativo que busca mostrar o grupo não apenas como um espaço de liberdade em meio ao endurecimento do regime, mas também como algo pioneiro.

No que tange a este objetivo, é necessário destacar a importância dos procedimentos cinematográficos, como a inserção de fotografias e cenas de apresentações ao longo das entrevistas presentes no filme, para confirmar os argumentos de sua atuação como elemento que transformou as normas comportamentais do período e pôs em xeque o status quo referente às normas socialmente estabelecidas sobre gênero, identidade e comportamento.

Como forma de confirmar tal argumento e mostrar as apresentações do conjunto teatral como representante de um espaço de liberdade em meio ao controle cada vez mais intenso que o governo militar exercia sobre a sociedade, destaca-se o uso do recurso de sobreposição rápida de sequências em preto-e-branco dos eventos políticos

\footnotetext{
3 Neste processo de representar Tatiana Issa, uma das diretoras do documentário, revisitando suas memórias, é necessário destacar o uso da narração in off e a sobreposição de imagens de sua infância com cenas dos bastidores do grupo com uma música de piano ao fundo entre os instantes 00:01:59 e 00:02:34 do documentário. Esta combinação de elementos diversos, como destaca Martin (2003), tem o intuito de mostrar os Dzi Croquettes como se estes fossem vistom pelos olhos da diretora quando criança.
} 
Revista do Corpo Discente do Programa de Pós-Graduação em História da UnB

EM TEMPO DE HISTóRIAS | Brasília-DF | n. 37 | p. 217-236 | jul./dez. 2020.

ISSN 2316-1191

às sequências fartamente coloridas das performances dos Dzi Croquettes ao início do filme, como no trecho entre os instantes 00:00:57 e 00:03:08 do documentário.

Estas sequência, em conjunto com o momento em que Issa retoma lembranças da infância, representadas também pela sobreposição de imagens dos camarins com sons que representam a repressão aos protestos, não têm função apenas estética, mas representam como destaca Martin (2003), uma aproximação simbólica das ações por meio do confronto de imagens dissonantes. Desta forma, por meio do recurso à montagem paralela e o flashback, o filme visa apresentar ao espectador por meio de uma imersão no contexto histórico e convencê-lo do papel importante desempenhado pelo grupo que é cerne da análise documental.

Desta forma, a memória antes fragmentada que é condensada e apresentada no filme não é um retrato que apresenta todos os fatos que circundavam a atuação do grupo, mas resultante de uma filtragem daquilo que é visto como mais importante de ser destacado para tirar o grupo do esquecimento em que se inseria. A exclusão destes aspectos acaba servindo como elemento que fornece harmonia ao enquadramento do documentário sobre o grupo, que cria uma aura sobre seu caráter de rebeldia que lhe é atribuído. Portanto, ao trazer ao público os argumentos aliados com as imagens e os efeitos cinematográficos, apreende-se o papel da montagem como processo que "casa a realidade objetiva do fenômeno com a atitude subjetiva do criador da obra" (EISENSTEIN, 1969 apud MARCEL, 2003, p.161).

Porém, mesmo com os problemas apresentados, é também fundamental destacar a importância deste filme de gênero documental em resgatar, em um aspecto mais amplo na historiografia que analisa a resistência ao regime militar, a ampliação das possibilidades de enfrentamento à Ditadura para além da atuação através da luta armada, onde a homossexualidade também era reprimida por ser vista como um vício pequeno-burguês (Cabral, 2016).

Este destaque a outras formas de enfrentamento não visa diminuir a importância da luta armada contra o governo militar, mas sim, destacar novas formas de exercício da oposição, especialmente aos ditames morais e comportamentais defendidos pela retórica conservadora que embasavam a visão de mundo da Ditadura. A ênfase na defesa da moral e dos bons costumes, neste caso, estava diretamente atrelada a um contexto em que estes

\begin{abstract}
valores e temores se tornaram, acima de tudo, questão de segurança nacional e foram instrumentalizados pelos grupos que estavam no poder no intuito de criar uma espécie de "histeria" dentro da sociedade, a fim de que obedecessem às determinações do Estado em relação aos mais variados aspectos da vida pública e privada. Entretanto, não se deve enfatizar apenas a dimensão "oportunista" dessa luta, já que o "perigo vermelho" era uma realidade naquele momento e foi combatido por grupos e indivíduos que viam o mundo pela ótica do anticomunismo, segundo a qual, a família, o casamento, a juventude e os valores da cristandade encontravam-se fortemente ameaçados (MOTTA, 2004, apud SETEMY, 2018, p.177).
\end{abstract}

Nesta conjuntura, ao resgatar o legado das performances dos Dzi Croquettes em um período onde a defesa da uniformidade e de rígido enquadramento às normas heteronormativas e de gênero se constituíam como parte importante do projeto 
Revista do Corpo Discente do Programa de Pós-Graduação em História da UnB

EM TEMPO DE HISTóRIAS | Brasília-DF | n. 37 | p. 217-236 | jul./dez. 2020.

ISSN 2316-1191

governamental de evitar o suposto projeto comunista de destruição das bases morais da sociedade, como destacado por Setemy (2018), o documentário destaca que sua atuação, por mais que não questionasse as desigualdades sociais ou as atrocidades cometidas pelo governo, ainda assim se constituía como elemento de atuação política.

Entretanto, como forma de exemplificar que o fechamento da ditadura impactou também o grupo, mesmo que este não criticasse o regime em si, é importante citar o trecho em que os diretores exploram o impacto da censura sobre a atuação, que teve como consequência a saída do grupo para o país em direção à Europa.

No trecho entre 01:04:20 e 01:06:28, há uma sequência de relatos de Ciro Barcelos, Cláudio Tovar e Benedicto Lacerda que narram especificamente o momento em que o sucesso do grupo passou a atrair olhares dos censores, que, mesmo não percebendo algo ameaçador no conteúdo das apresentações propriamente ditas, viam o uso da androginia e da transgressão de valores por meio da linguagem visual e corporal como uma ameaça à moral e aos bons costumes.

Tovar narra que, como Lennie Dale havia sofrido um grave acidente, foi convocado em seu lugar para dar explicações sobre as apresentações. Embora posteriormente a apresentação tenha sido liberada, relata que sofreu ameaças se não cumprisse as ordens que foram estabelecidas.

Torceram pauzinhos, e conseguimos uma entrevista com o diretor de censura, chefe de censura. E ele chamou o chefe do grupo. Seria o Lennie, que ele queria falar, né? O Lennie tinha sido atropelado por um ônibus, tava num hospital, não podia ir [...] Então, lá fui eu falar com este coronel sei lá o quê. Me xingou de todos os nomes possíveis: "Se você repetir o que vocês fizeram, acabo com você"!(DZI CROQUETTES, 2009, 01:04:52 - 01:05:34).

O destaque à esta sequência, permite apreender, portanto, que, mesmo que os diretores não estabeleçam para além de episódios esporádicos os impactos dos Anos de Chumbo, visto que o foco da narrativa está muito mais centrado em destacar a sua atuação no período, ainda assim objetiva-se mostrar que o grupo, mesmo não aderindo a uma via de engajamento, também foi impactado pelo contexto político e social que o circundava.

Em suma, destaca-se a sua atuação como política ao dialogar com aspectos referentes ao âmbito coletivo e seus anseios, como os novos comportamentos, a busca pela liberdade sexual, e etc, que por sua vez representaram uma via de confronto aos valores defendidos pelos militares no poder. No documentário, este aspecto se faz evidente na fala do diretor de teatro José Possi Neto em entrevista aos diretores.

\footnotetext{
Eles não tavam (sic) nem um pouco engajados com política institucional. Mas é claro que era político. Qualquer ato é político. E havia uma revolução de comportamento, e liberação sexual e de valores morais com relação à masculinidade e feminilidade, que eles são o grande grito (DZI CROQUETTES, 2009, 00:12:24 - 00:12:44).
}

Todavia, deve-se destacar que, embora o documentário seja um importante meio de apresentar a um público mais amplo os impactos que o grupo legou no âmbito do teatro, da música e da desconstrução das normas tradicionais de gênero e sexualidade, 
Revista do Corpo Discente do Programa de Pós-Graduação em História da UnB

Em TEMPO DE HISTóRIAS | Brasília-DF | n. 37 | p. 217-236 | jul./dez. 2020.

ISSN 2316-1191

ainda assim, vê-se como necessária uma análise crítica de como este legado é resgatado e apresentado.

\section{Conclusão}

É importante destacar as interlocuções que podem ser estabelecidas entre a memória e a história, pensando estes dois campos não como elementos antagônicos, porém com características específicas, especialmente na forma como lidam com o passado. E é interessante destacar também como o documentário representa um espaço de comunicação entre as duas áreas e enquanto elemento de preservação de eventos ligados à atuação de personagens até então não presentes nas narrativas historiográficas, seja sobre a ditadura, homossexualidade ou contracultura, assim como elemento que organiza estas lembranças até então fragmentadas.

Após décadas de apagamento no espaço artístico e acadêmico, o documentário Dzi Croquettes (2009) é pensado como instrumento importante de retomada de memórias sobre a Ditadura Militar, a contracultura e a homossexualidade no âmbito brasileiro. Se tais memórias anteriormente não eram incluídas nas análises acadêmicas sobre a resistência no período dos Anos de Chumbo (1968-1975), o filme traz de forma mais ampla, a importância de considerar novas vias de embates ao regime, principalmente pela via comportamental que se iniciam a partir do início da contracultura.

É também importante o fato de se destacar que a origem do grupo, embora tome como inspiração o nome de um grupo de teatro nova-iorquino conhecido como The Cockettes, não sendo é um simples abrasileiramento da contracultura estadunidense, visto que toma como fontes de inspiração os carnavais de rua carioca e os espetáculos de cabaré, segundo Vicente (2013).

Ao se falar da criação do grupo, os relatos de Bayard Tonelli, a Bacia, e também de Lacerda, deixa-se claro a intenção do grupo em posicionar-se não apenas como uma paródia da citada trupe estadunidense, mas como forma de deixar claro a concepção que tinham a respeito da fluidez das identidades de gênero.

O nome do salgado, portanto, revela simultaneamente um desejo de parodizar, mas também de mostrar a ideia de que se viam como "apenas gente", como expresso no trecho entre os instantes 00:14:52 e 00:14:58 do documentário, transcendendo as limitações de papéis de gênero e identidades fixas defendidas no período. Ou seja, como destacado no documentário, a escolha deste nome não foi fruto apenas pelo fato de estarem comendo croquetes quando surgiu a ideia de montar um espetáculo e nomeá-lo, como destacado no trecho entre 00:28:29 e 00:29:06, mas também em decorrência da forma como viam a questão das identidades representadas por meio do corpo. Como resumido na fala de Lacerda, se viam apenas como sendo "croquete (sic), porque somos feitos de carne” (DZI CROQUETTES, 2009, 00:29:06-00:29:12).

Desta forma, as suas performances e a exibição de seus corpos em figurinos andróginos a um público, que os "consumiam" no sentido de os assistirem, ao verem através de seus corpos a mistura entre gêneros, vislumbravam uma nova possibilidade 
Revista do Corpo Discente do Programa de Pós-Graduação em História da UnB

Em TEMPO dE HISTÓRIAS | Brasília-DF | n. 37 | p. 217-236 | jul./dez. 2020.

ISSN 2316-1191

de vivências para além de padrões rígidos. Destacando a posição à margem da indústria ocupada pelo grupo enquanto parte do teatro, é necessário sublinhar a visibilidade restrita que suas performances tiveram. Entretanto, é importante também salientar como, mesmo à um nível restrito, tais propostas representaram um espaço de discussão das masculinidades e feminilidades em voga no período.

Embora o grupo tenha representado de fato uma novidade na cena teatral brasileira do período pelas suas propostas, é de suma importância salientar que este não pode ser analisado como fator deslocado de um contexto mais amplo de mudanças comportamentais, morais e sexuais que já vinha ganhando espaço desde o advento da Tropicália.

Ao mesmo tempo, como destaca Parker (2002), a conjuntura em que o grupo atuou foi marcada pelo surgimento de uma cultura homossexual no Rio de Janeiro, cidade em que o grupo foi fundado. Motivada pela urbanização e crescimento econômico, homossexuais da classe média eram desejosos de possuírem espaços próprios para sua socialização. Destaca-se no documentário, que são nestes espaços, frequentados por um público não-heteronormativo, que o grupo inicia suas apresentações. ${ }^{4}$ Porém, não se relaciona a existência destes espaços com processos socioeconômicos que permitiram seu florescimento, assim como não se relaciona a influência do advento da contracultura como contexto que permitiu um campo fértil para o surgimento do grupo.

Sublinhar estes fatores não significa retirar dos Dzi Croquettes o seu aspecto original e de impacto, especialmente ao se utilizarem de uma estética andrógina que punha em xeque definições fixas sobre gênero e sexualidade. Mas, no caso do documentário, é necessário se atentar que o contexto em que o grupo atuou, mesmo com a censura e a repressão que o caracterizaram, já se presenciava, como argumento Castelo Branco (2006) discussões sobre novas formas de comportamento e relações.

Destacar esta conjuntura, portanto, é importante para compreender os Dzi Croquettes como grupo que traz novidades, mas ao mesmo tempo, também carrega em sua trajetória influências de um contexto de efervescência cultural e social. Ou seja, "se não formos capazes de ver um elemento superestrutural, não seremos capaz de reconhecer a realidade" (WILLIAMS, p.51), acarretando, por consequência uma narrativa que idealiza a sua atuação sem levar em conta a teia de relações em que estavam inseridos.

Esta teia de relações é composta, portanto, pelo contexto de mudanças comportamentais, culturais e socioeconômicas que já vinham tomando forma anteriormente ao surgimento dos Dzi Croquettes propriamente ditos. Nos dois primeiros aspectos, há que se destacar os questionamentos sobre os limites de gênero e sexualidades, iniciados já por grupos anteriores, como a Tropicália, que marcou a gênese da contracultura brasileira. Influenciados por esse princípio e pelo

\footnotetext{
4 Ciro Barcellos, em entrevista ao documentário, argumenta que o grupo realizou sua primeira apresentação, com texto de Wagner Ribeiro, no Cabaret Casanova, situado na região da Lapa, no Rio de Janeiro. Na sequência de 00:30:23 a 00:30:26, em filmagem com travelling para frente, é apresentado o lugar do primeiro espetáculo. O uso deste recurso tem o intuito de representar um retorno mental ao passado que é descortinado através dos relatos.
} 
Revista do Corpo Discente do Programa de Pós-Graduação em História da UnB

EM TEMPO DE HISTóRIAS | Brasília-DF | n. 37 | p. 217-236 | jul./dez. 2020.

ISSN 2316-1191

experimentalismo, o citado grupo é aqui compreendido como resultado de um processo de amadurecimento dos preceitos anteriores, e não como um elemento inédito e sem precedentes.

No contexto socioeconômico, é importante salientar também o surgimento de espaços de socialização voltados a um público homossexual de classe média decorrentes do processo de crescimento econômico e do público consumidor, que permitiu ao grupo, espaços onde pudessem exercitar com mais liberdade as suas performances, que marcam um processo de radicalização dos questionamentos sobre gênero, sexualidade e identidade.

Levando em conta que o filme é concebido como aporte para celebrar o legado do supracitado grupo, como consequência, o seu enfoque acaba sendo mais centrado em mostrar os seus impactos no período e para a posteridade do que analisar o contexto sócio-histórico e cultural que permitiu sua atuação.

Visto que o filme finalizado é resultado de uma seleção dos fatos narrados, não representando a realidade em toda a sua totalidade, deve-se destacar, como conclusão, que a memória que resgata de um grupo até então marginalizado, não é isenta. Ao lhe atribuir características que não eram inerentes à sua atuação, como no supracitado trecho em que o grupo é apresentado como precursor do movimento LGBT brasileiro, ignorando que tanto o movimento quanto a sigla são posteriores ao período histórico em que o grupo atuou, percebe-se que leva-se ao público uma memória que reflita uma postura de idealização.

Consequentemente, é de suma importância pensar como o documentário, enquanto fonte, possibilita trazer novas discussões sobre o período através do uso das memórias e pensar a importância dos relatos como materiais de análise que permitem apreender a atuação da população homossexual no período mais repressivo do regime. E, pensar o papel do cinema, em conjunto com a história oral, como instrumentos que permitem ampliar os olhares da historiografia para novas facetas referentes às temáticas da Ditadura, contracultura e homossexualidade, porém, não esquecendo os aspectos de seleção relacionados à memória, oralidade e à linguagem cinematográfica.

\section{Referências}

ADORNO,Theodor; HORKHEIMER, Max. A indústria cultural: o iluminismo como mistificação de massas. In: THEODOR, Adorno. Indústria Cultural e Sociedade. Tradução de Juba Elisabeth Levy. 5. ed. São Paulo: Paz e Terra, 2009, p.5-49.

BARROS, José D’Assunção. Cinema-História: Múltiplos aspectos de uma relação. Dispositiva. Belo Horizonte, v.3, n.1, p.17-40, 2014. Disponível em: <http://periodicos.pucminas.br/index.php/dispositiva/article/view/11551/9291>. Acessado em 01 dez. 2019.

BRAGA, Cíntia Guedes. Desejos desviantes e imagens cinematográficas: a construção da subjetividade não heterossexual no cinema brasileiro contemporâneo. 2015. 150f. Dissertação (Mestrado em Cultura e Sociedade). Instituto de Humanidades, Artes e Ciências, Universidade Federal da Bahia, 2015. 
Revista do Corpo Discente do Programa de Pós-Graduação em História da UnB

EM TEMPO DE HISTóRIAS | Brasília-DF | n. 37 | p. 217-236 | jul./dez. 2020.

ISSN 2316-1191

CASTELO BRANCO, Edwar de Alencar. Ele é o homem, eu sou apenas uma mulher: corpo, gênero e sexualidade entre as vanguardas tropicalistas. 2006. In: Fazendo Gênero, 7., Gênero e Preconceitos. Anais Eeletrônicos. Florianópolis: UFSC, 2006, p.17.

Disponível

em: $<$ http://www.fazendogenero.ufsc.br/7/artigos/E/Edwar_de_Alencar_Castelo_Branco_16. pdf >. Acessado em: 08 jul. 2019, às 13h36min.

CORDEIRO, Janaína Martins. Anos de chumbo ou anos de ouro? A memória social sobre o governo Médici. Estudos Históricos. Rio de Janeiro, v.22, n.43, p.85-104, janjun. 2009. Disponível em: <http://www.scielo.br/pdf/eh/v22n43/v22n43a05.pdf>. Acessado em 23 dez. 2019.

DINIZ, Sheyla Castro. Desbundados e Marginais: A MPB "pós-tropicalista" no contexto dos Anos de Chumbo. In: Congresso Internacional da Brazilian Studies Association, 12., Anais Eletrônicos. Londres: King's College, 2016, p.1-15. Disponível em:

<http://www.brasa.org/wordpress/Documents/BRASA_XII/Proceedings/Sheyla\%20Cast ro\%20Diniz\%20-\%20Desbundados\%20e\%20Marginais.pdf>. Acessado em 23 dez. 2019.

DZI CROQUETTES. Direção: Tatiana Issa e Raphael Alvarez. Produção: TRIA PRODUCTIONS e Produções Artísticas e Canal Brasil. Roteiro de Tatiana Issa e Raphael Alvarez. Rio de Janeiro: TRIA PRODUCTIONS e Produções Artísticas. Distribuição: Imovision, 2009. 110 min., son., color. Disponível em: <https://www.youtube.com/watch?v=OGrIMj-4UWc>. Acessado em 13 abr. 2019.

EISENSTEIN, Serguei Mikhailovitch. Reflexões de um cineasta. Tradução de Gustavo A. Dória. 1. ed. Rio de Janeiro: Zahar Editores, 1969, p.151.

ENTREVISTA com Tatiana Issa e Raphael Alvarez. [S.1]: Saraiva Conteúdo, 2010. (6min48seg). Disponível em: <https://www.youtube.com/watch?v=XINnOZpoDc0>. Acessado em 11 set. 2019..

FACCHINI, Regina. Múltiplas identidades, diferentementes enquadramentos e visibilidades: um olhar para os 40 anos do movimento LGBT. In: GREEN, James et al. História do Movimento LGBT no Brasil. 1. ed. São Paulo: Alameda, 2018, p.311-329.

GINZBURG, Carlo. O queijo e os vermes - O cotidiano de um moleiro perseguida pela Inquisição. Tradução de Maria Betânia Amoroso. 1. ed. São Paulo: Companhia de Bolso, 2006.

GREEN, James Naylor. Revolucionário e gay: a vida extraordinária de Herbert Daniel - pioneiro na luta pela democracia, diversidade e inclusão. Tradução de Marília Sette Câmara. 1. ed. Rio de Janeiro: Civilização Brasileira, 2018.

GUILHERMETI, Paulo; KNUPPEL, Maria Aparecida Crissi. Memória, Esquecimento e Experiência nos Meios de Comunicação: apontamentos a partir da teoria crítica. In: Encontro Nacional de História da Mídia, 8. Anais Eletrônicos. Guaruapuava: Unicentro, 2011, p.1-10. Disponível em: <http://www.ufrgs.br/alcar/encontrosnacionais-1/encontros-nacionais/8o-encontro-2011-1/artigos/Memoria$\% 20$ esquecimento $\% 20 \mathrm{e} \% 20$ experiencia $\% 20$ nos $\% 20$ meios $\% 20 \mathrm{de} \% 20$ comunicacao $\% 20$ ap 
Revista do Corpo Discente do Programa de Pós-Graduação em História da UnB

Em TEMPO DE HISTóRIAS | Brasília-DF | n. 37 | p. 217-236 | jul./dez. 2020.

ISSN 2316-1191

ontamentos\%20a\%20partir\%20da\%20teoria\%20critica.pdf/view>. Acessado em 13 abr. 2020 .

GUTFREIND, Cristiane Freitas. O cinema como objeto de comunicação histórica. In: Revista Fronteiras. São Leopoldo, v.2, n.1, p.47-52, 2005. Disponível em: $<$ http://revistas.unisinos.br/index.php/fronteiras/article/view/6383>. Acessado em 24 dez. 2019.

HOLLANDA, Heloísa Buarque de. Impressões de viagem: CPC, vanguarda e desbunde, 1960/1970. 2. ed. São Paulo: Brasiliense, 1981.

ISIDIO, Jean. O cinema e a indústria cultural. In: VIANA, Nildo (org). Indústria Cultural e Cultura Mercantil. 1. ed. Corifeu: Rio de Janeiro, 2007, p.56-65.

MARTIN, Marcel. A linguagem cinematográfica. Tradução de Paulo Neves. 1. ed. São Paulo: Brasiliense, 2003.

MENEZES, Paulo Roberto Arruda de. Cinema: Imagem e Interpretação. In: Tempo Socia. São Paulo, vol. 8, n.2, 1996, p.83-104. Disponível em: <http://www.revistas.usp.br/ts/article/view/86299/88961>. Acessado em 01 dez. 2019.

MOTTA, Rodrigo Patto Sá. O anticomunismo militar. In: UNIVERSIDADE FEDERAL DO RIO DE JANEIRO - UFRJ et al. 1964-2004: 40 anos do golpe. Ditadura militar e resistência no Brasil. $1^{\mathrm{a}}$ ed. Rio de Janeiro: 7 Letras/FAPERJ, 2004, p. 292.

NAPOLITANO, Marcos. A História depois do papel. In: PINSKY, Carla Bassanezi (Org). Fontes Históricas. São Paulo: Contexto, 2005. p.235-289.

NICHOLS, Bill. Introdução ao documentário. Tradução de Mônica Saddy Martins. 5. ed. São Paulo: Papirus, 2010.

NORA, Pierre. Entre Memória e História - A problemática dos lugares. Tradução: Yara Aun Khoury. In: Projeto História. São Paulo, v.10, p.7-28, jul./dez. 1993. Disponível em: <https://revistas.pucsp.br/index.php/revph/article/view/12101>. Acessado em 25 abr. 2019.

OCANHA, Rafael. Amor, Feijão, Abaixo Camburão - Imprensa, Violência e Trottoir em São Pulo (1979-1983). 2014. 217p. Dissertação (Mestrado em História). Pontífica Universidade Católica, São Paulo, 2014. Disponível em: $<$ https://sapientia.pucsp.br/bitstream/handle/12830/1/Rafael\%20Freitas\%20Ocanha.pd f>. Acessado em: 9 de fev. 2017

PARKER, Richard. História de duas cidades. In: Abaixo do equador - Culturas do desejo, homossexualidade masculina e comunidade gay no Brasil. Tradução de Ryta Vinagre. 1. ed. Rio de Janeiro: Record, 2002. cap.5.

PEREIRA JUNIOR, Jurandir Eduardo. Nem homem, nem mulher, gente: trajetória do grupo Dzi Croquettes entre o passado e reflexões no presente. 2016. 207f. Dissertação (Mestrado em Teatro) - Departamento de Arte, Universidade do Estado de Santa Catarina, Florianópolis.

Disponível em: $<$ http://sistemabu.udesc.br/pergamumweb/vinculos/000013/00001333.pdf>. Acessado em 27 mar. 2019. 
Revista do Corpo Discente do Programa de Pós-Graduação em História da UnB

Em TEMPO dE HISTÓRIAS | Brasília-DF | n. 37 | p. 217-236 | jul./dez. 2020.

ISSN 2316-1191

POLLAK, Michael. Memória, Esquecimento, Silêncio. In: Estudos Históricos. Rio de Janeiro, vol. $2 . \quad$ n. $3, \quad 1989$, p.3-15. Disponível em: $<$ http://www.uel.br/cch/cdph/arqtxt/Memoria_esquecimento_silencio.pdf $>$. Acessado em 2 abr. 2019.

SEIXAS, Xosé Pereira Nuñez. La Historia Social ante el domínio de la Historia Social. In: Historia Social. Valencia, n.60, 2008, p.177-184.

SETEMY, Adrianna Cristina Lopes. Vigilantes da moral e dos bons costumes: condições sociais e culturais para a estruturação política da censura durante a ditadura militar. In: Topoi - Revista de História: Programa de Pós-Graduação em História Social da UFRJ, Rio de Janeiro, vol.19, n.37, p.171-197, jan./abr. 2018. Disponível em: <http://www.scielo.br/pdf/topoi/v19n37/2237-101X-topoi-19-37171.pdf $>$. Acessado em 22 dez. 2019.

THOMPSON, John Brookshire. Mídia e Modernidade. Tradução de Wagner de Oliveira Brandão. 5. ed. Petrópolis: Vozes, 1998.

VICENTE, Keides Batista. Nos não somos mulheres também não, (...) nós somos gente. Androgenia, dança e contestação política durante a Ditadura Militar no Brasil. 2013. In: Simpósio Nacional de História, 27., Anais Eletrônicos. Natal: UFRN, 2013. Disponível em:

http://www.snh2013.anpuh.org/resources/anais/27/1364168062_ARQUIVO_anphu2013 .pdf $>$. Acessado em: 17 jun. 2017.

WILLIAMS, Raymond. Base e superestrutura na teoria da cultura marxista. In: . Cultura e materialismo. Tradução de André Glaser. $1^{a}$ ed. São Paulo: Editora

UNESP, 2011. 